\title{
Parâmetros físicos do solo e erosão hídrica sob chuva simulada, em área de integração agricultura-pecuária ${ }^{1}$
}

\author{
Elói Panachuki ${ }^{2}$, Teodorico Alves Sobrinho ${ }^{2}$, Antônio C. T. Vitorino², Daniel F. de Carvalho ${ }^{3}$ \& Mário A. Urchei ${ }^{4}$
}

\begin{abstract}
RESUMO
Este trabalho foi realizado em Dourados, MS, com o objetivo de se avaliar as perdas de solo e de água em pastagens e em plantio direto, em área cultivada no sistema de integração agricultura-pecuária, utilizando-se um simulador de chuva portátil. Estudou-se o efeito de quatro intensidades de precipitação $\left(40,60\right.$, 80 e $\left.100 \mathrm{~mm} \mathrm{~h}^{-1}\right)$, as quais constituíram quatro tratamentos, dispostos em um delineamento experimental de blocos casualizados, com quatro repetições. Os valores médios acumulados de perdas de solo variaram de 1,33 a 10,50 $\mathrm{g} \mathrm{m}^{-2}$ e as perdas de água assumiram valores variáveis entre $1,34 \times 10^{-3}$ e $34,64 \times 10^{-3} \mathrm{~m}^{3} \mathrm{~m}^{-2}$. As maiores intensidades de precipitação promoveram também maiores perdas de solo e de água, com maior perda de solo no plantio direto e maior perda de água na pastagem.
\end{abstract}

Palavras-chave: sistemas de cultivo, perda de solo, simulador de chuvas

\section{Physical parameters of soil and erosion under simulated rainfall, in pasture-agriculture integration system}

\begin{abstract}
This work was carried out in Dourados, Mato Grosso do Sul State, Brazil, in order to evaluate soil erosion and water loss in pasture and in no tillage agriculture in a pasture-agriculture integration system using a portable rainfall simulator. Four rainfall intensities $\left(40,60,80\right.$ and $\left.100 \mathrm{~mm} \mathrm{~h}^{-1}\right)$ were studied, each consisting of a treatment arranged in an experimental design in randomized blocks with four replications. Accumulated average soil loss varied from 1.33 to $10.50 \mathrm{~g} \mathrm{~m}^{-2}$ and water loss varied from $1.34 \times 10^{-3}$ to $34.64 \times 10^{-3} \mathrm{~m}^{3} \mathrm{~m}^{-2}$. The largest soil and water losses occured in the largest rainfall intensities and the no-tillage system had the largest soil loss and the pasture the largest water loss.
\end{abstract}

Key words: tillage system, soil loss, rainfall simulator

1 Parte da Dissertação de Mestrado do primeiro autor apresentada à UFMS, Dourados, MS, desenvolvida com apoio financeiro do CNPq 2 UFMS. Cidade Universitária, CP 533, CEP 79804-970, Dourados, MS. Fone: (67) 3411-3849. E-mail: eloip@dourados.br; talves@nin.ufms.br; vitorino@ceud.ufms.br 3 UFRRJ. BR 465, Km 7, CEP 23890-000, Seropédica, RJ. Fone: (21) 3787-3742. E-mail: carvalho@ufrrj.br. Bolsista do CNPq

${ }^{4}$ EMBRAPA/CPAO. Rodovia Dourados - Caarapó, Km 8, CEP:79823-490, Dourados, MS. Fone: (67) 425-5122. E-mail: urchei@cpao.embrapa.br 


\section{INTRODUÇÃO}

A erosão hídrica é o processo de degradação do solo que mais tem afetado a capacidade produtiva dos solos, facilitada e acelerada por interferência antrópica que, na maioria das vezes, resulta num processo de erosão acelerada. A degradação dos solos pode ser considerada um dos mais importantes problemas ambientais nos dias atuais, resultante de práticas inadequadas de manejo agrícola. Esse desgaste do solo deve ser compreendido quando se objetiva a manutenção ou o aumento da produtividade agrícola e a conservação ambiental, favorecendo a sustentabilidade de agroecossistemas.

O processo erosivo consiste de três eventos seqüenciais, caracterizados pelo desprendimento, arraste e deposição das partículas do solo. O desprendimento é definido como a liberação de partículas dos agregados e, uma vez desprendidas, elas podem permanecer próximas ao agregado ou serem transportadas (Carvalho et al., 2002). O desprendimento ou desagregação das partículas ocorre pelo efeito integrado da energia de impacto das gotas de água e da força cisalhante do escoamento superficial constituindo, assim, o estágio inicial e mais importante do processo da erosão hídrica. O arraste, ou transporte das partículas, é feito pela ação do vento e, em maior escala, pelo escoamento superficial da água como veículo. O estágio final do processo, a deposição das partículas, normalmente culmina nos corpos de água, tendo como resultado o assoreamento dos leitos dos rios.

O sucesso de uma exploração agropecuária equilibrada depende, em grande parte, da investigação e controle dos aspectos referentes aos agentes causadores da erosão, como as chuvas e certos atributos do solo que, pela ação antrópica, podem favorecer ou dificultar o processo erosivo, já que as atividades humanas constituem os principais agentes catalisadores desses processos.

É notório que na agropecuária intensiva, com o uso e o manejo muitas vezes inadequados do solo, ocorre a substituição da cobertura de vegetação natural de grandes áreas e disso usualmente se origina o processo de degradação do solo e dos recursos hídricos. Esta deterioração tem, como conseqüência, uma série de mudanças físicas, químicas, biológicas e hidrológicas, provocando a diminuição da capacidade produtiva do solo.

De acordo com Silva et al. (2000) a erosão hídrica deve ser estudada considerando-se a erodibilidade do solo, que representa o efeito integrado dos processos que regulam a infiltração de água e a resistência do solo à desagregação e transporte de partículas, ou seja, sua predisposição a erosão. É o fator que tem despertado o maior interesse na pesquisa da erosão, por ser governado pelos atributos intrínsecos do solo, os quais podem variar de um solo para solo outro, ou para o mesmo solo, a depender do tipo de manejo.

Uma das maneiras utilizadas para estimar a erodibilidade consiste na correlação entre a característica da chuva e as perdas de solo observadas em parcelas experimentais com chuva simulada. Esta metodologia apresenta a vanta- gem de agilizar a obtenção de dados importantes a respeito de práticas de manejo do solo e culturas, visando à conservação do solo e da água, porém a principal limitação na utilização de chuva simulada é a impossibilidade de reproduzir as características das chuvas naturais, em termos de intensidade, duração e energia de impacto das gotas de chuva, além das dificuldades de se compararem os resultados obtidos, tendo em vista o uso de consideráveis diversificações de simuladores de chuva, intensidades de chuva e tipos de parcela (Eltz et al., 2001).

Algumas práticas de manejo do solo, segundo Carpenedo \& Mielniczuk (1990) promovem modificações nas propriedades físicas do solo, principalmente na sua estrutura, podendo tais alterações ser permanentes ou temporárias e, ainda, influenciarem grandemente o processo erosivo. Assim, o solo submetido ao cultivo intensivo tem a sua estrutura original alterada com fracionamento dos agregados em unidades menores e conseqüente redução no volume de macroporos e aumentos no volume de microporos e na densidade do solo.

Hernani et al. (1997) realizaram estudos visando quantificar as perdas de solo por erosão em diferentes sistemas de preparo em Latossolo Roxo, em Dourados, MS; neste estudo, os autores concluíram que o plantio direto foi o sistema mais eficiente no controle de perdas de solo e de água. As perdas médias de solo por erosão, relativas aos sistemas de plantio direto, escarificação e gradagem niveladora, gradagem pesada e gradagem niveladora e aração com arado de discos e duas gradagens niveladoras, sem cobertura vegetal foram, respectivamente, 0,8 ; 2,8; 5,3; 7,3 t ha-1 ano $^{-1}$; no entanto, referidos trabalhos foram feitos com parcelas fixas e com chuva natural, o que dificulta sua condução em outras condições de solo e de manejo.

Comparando diferentes sistemas de preparo e cultivo do solo, Schick et al. (2000) concluíram que o sistema plantio direto é mais eficaz no controle das perdas de solo, reduzindo-as em 68 e 52\%, em relação ao manejo com uma aração associada a duas gradagens e escarificação associada a uma gradagem, respectivamente. As perdas de água seguem a mesma tendência, sendo menos influenciadas que as perdas de solo.

Em trabalho semelhante, Cogo et al. (2003) consideram que a cobertura do solo proporcionada pelos resíduos culturais deixados na superfície, tem ação direta e efetiva na redução da erosão hídrica, em virtude da dissipação de energia cinética das gotas de chuva, a qual diminui a desagregação das partículas de solo e o selamento superficial e aumenta a infiltração de água, atuando ainda na redução da velocidade do escoamento superficial e, conseqüentemente, da capacidade erosiva da enxurrada.

Tendo em vista a importância de se obter conhecimentos adicionais sobre a erodibilidade do solo em diferentes sistemas agropecuários tem-se, com o presente trabalho, o objetivo de avaliar o comportamento dos diferentes parâmetros físicos do solo na erosão hídrica de um solo muito argiloso, utilizando-se um simulador de chuva portátil, cultivado no sistema de integração agricultura-pecuária. 


\section{MATERIAL E MÉTODOS}

O trabalho foi realizado no Centro de Pesquisa Agropecuária d'Oeste (EMBRAPA/CPAO), em Dourados, MS (latitude Sul $22^{\circ}$ 14', longitude a Oeste de Greenwich 54 ${ }^{\circ}$ 49' e altitude média de $452 \mathrm{~m}$ ), no período compreendido entre março e julho de 2003. A declividade média da área experimental é de $0,03 \mathrm{~m} \mathrm{~m}^{-1}$. O solo, classificado como Latossolo Vermelho aluminoférrico típico, possui textura muito argilosa, com $710 \mathrm{~g} \mathrm{~kg}^{-1}$ de argila, $175 \mathrm{~g} \mathrm{~kg}^{-1}$ de silte e $115 \mathrm{~g} \mathrm{~kg}^{-1}$ de areia e apresenta, em superfície, uma camada delgada com estrutura laminar. O clima regional classificado pelo sistema internacional de Köppen é do tipo Cwa, clima úmido e inverno seco, com precipitação média anual de $1500 \mathrm{~mm}$ e temperatura média anual de $22{ }^{\circ} \mathrm{C}$.

As avaliações referentes às perdas de solo e de água a campo, sob diferentes intensidades de precipitação e sistemas de cultivo, foram feitas através do infiltrômetro de aspersão, denominado InfiAsper/UFMS, desenvolvido por Alves Sobrinho (1997). O infiltrômetro, ou simulador de chuvas portátil, foi calibrado para aplicar intensidades de precipitação de 40, 60, 80 e $100 \mathrm{~mm} \mathrm{~h}^{-1}$, operando com $32 \mathrm{kPa}$ de pressão de serviço. A área de ação do equipamento, ou área da parcela experimental $\left(0,70 \mathrm{~m}^{2}\right)$, foi contornada por um dispositivo de formato retangular, construído em chapas de aço galvanizado número 16 , para permitir a obtenção do volume de água escoado superficialmente.

As estimativas das perdas de solo e de água foram realizadas em dois sistemas de integração agricultura-pecuária, denominados sistema A e sistema B. A área experimental correspondente ao sistema A estava sendo cultivada com pastagem, enquanto na área do sistema $\mathrm{B}$ havia resteva de soja, cultivada sob plantio direto, durante o período dos testes de campo com o simulador de chuvas. O histórico de uso das áreas correspondentes aos sistemas de rotação, com as respectivas culturas utilizadas desde 1995, está apresentado na Tabela 1.

Em cada sistema foi delineado um experimento para determinação das perdas de solo e de água, com quatro tratamentos para cada uma das áreas experimentais (sistemas A e B). Os tratamentos corresponderam aos valores de inten-

Tabela 1. Histórico das espécies vegetais cultivadas nos sistemas $A$ (pastagem) e B (plantio direto), no período compreendido entre 1995 e 2003

\begin{tabular}{|c|c|c|c|c|c|}
\hline \multirow{2}{*}{ Ano } & \multicolumn{2}{|c|}{ Sistemas } & \multirow{2}{*}{ Ano } & \multicolumn{2}{|c|}{ Sistemas } \\
\hline & A & B & & A & B \\
\hline 1995 & Milho & Milho & $99 / 00$ & Soja & $\mathrm{BD}$ \\
\hline $95 / 96$ & Soja & $\mathrm{BD}$ & 2000 & Aveia & $\mathrm{BD}$ \\
\hline 1996 & Aveia & $B D$ & $00 / 01$ & Soja & BD \\
\hline $96 / 97$ & Soja & $B D$ & 2001 & Aveia & $\mathrm{BD}$ \\
\hline 1997 & Aveia & $B D$ & $01 / 02$ & BD & Soja \\
\hline $97 / 98$ & $\mathrm{BD}^{1}$ & Soja & 2002 & $B D$ & Aveia \\
\hline 1998 & $\mathrm{BD}$ & Aveia & $02 / 03$ & BD & Soja \\
\hline $98 / 99$ & $\mathrm{BD}$ & Soja & 2003 & BD & Aveia \\
\hline 1999 & BD & Aveia & & & \\
\hline
\end{tabular}

${ }^{1}$ BD - Fonte: EMBRAPA/CPAO Brachiaria decumbens sidade de precipitação (40; 60; 80 e $100 \mathrm{~mm} \mathrm{~h}^{-1}$ ), dispostos no delineamento experimental de blocos casualizados, com quatro repetições, totalizando 16 parcelas experimentais em cada um dos sistemas.

O aspecto da cobertura do solo de duas parcelas experimentais, utilizadas para as determinações de perda de solo e de água, pode ser visualizado na Figura 1.

As parcelas, que eram avaliadas geralmente em número de duas por dia, recebiam um pré-molhamento $24 \mathrm{~h}$ antes de se iniciar a coleta dos dados de escoamento superficial. O objetivo desse pré-molhamento era o de oferecer condições de umidade mais uniforme às parcelas teste, constituindo um pré-requisito antes da aplicação da chuva artificial para determinação de perda de solo; para isto, o simulador era regulado para aplicar uma intensidade de chuva de $60 \mathrm{~mm} \mathrm{~h}^{-1}$, em tempo suficiente para saturar o solo sem que houvesse escoamento superficial e, conseqüentemente, carreamento de solo para a calha coletora.

Em cada parcela experimental foi determinada a umidade inicial do solo, momentos antes dos testes de campo; para
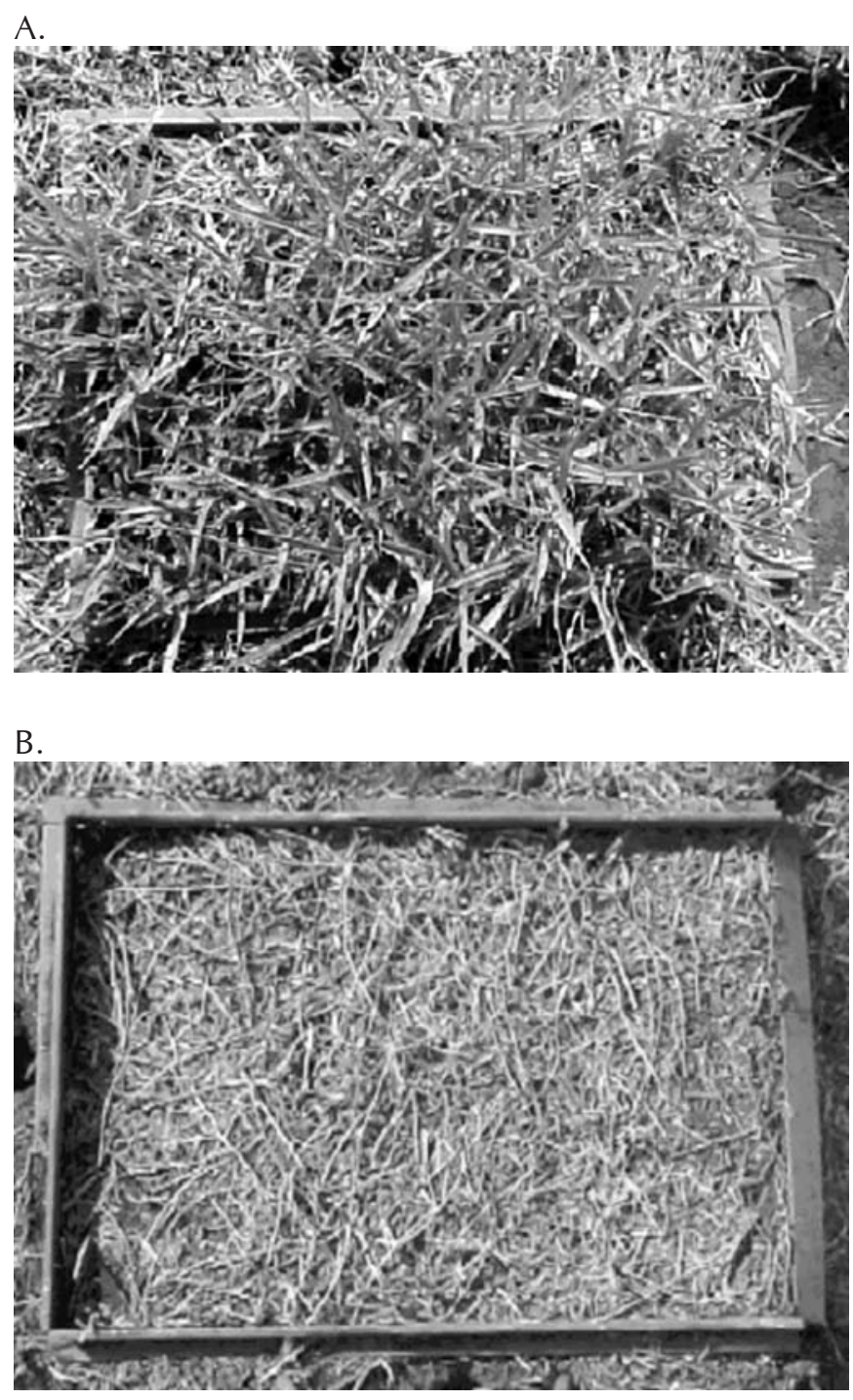

Figura 1. Parcelas dos sistemas de integração agricultura-pecuária: com cultivo de Brachiaria decumbens (A) e com resteva de soja (B) 
tanto, amostras de solo foram coletadas com auxílio de trado, em três profundidades (0-5; 5-10 e 10-20 cm) e se determinou a umidade do solo pelo método padrão de estufa (Tabela 2).

Efetuou-se a análise estatística para os dados de umidade inicial, com o objetivo de se constatar a eficiência do prémolhamento, conferindo condições equivalentes de umidade a todas as áreas que receberam os tratamentos. Ao se analisar os dados da umidade inicial, observa-se que não houve diferença estatística significativa entre eles, fato que pode ser atribuído ao efetivo pré-molhamento das parcelas.

As avaliações de perda de solo e de água foram iniciadas, então, 24 h após o pré-molhamento, coletando-se sete amostras do volume escoado em cada parcela experimental. Utilizaram-se frascos plásticos com capacidade de um litro e intervalo de tempo de 5 min entre cada amostra, conforme descrito por Varella (1999). A coleta da primeira amostra era feita quando o escoamento de água na calha coletora se iniciava. Se depois de decorrido o intervalo de tempo o recipiente não estivesse ainda completamente cheio, a coleta seria interrompida, o frasco vedado e imediatamente se iniciava a coleta da amostra seguinte. Caso contrário, se o recipiente ficasse completamente cheio antes de decorrido o intervalo de tempo, a coleta seria interrompida e o tempo de enchimento do frasco, registrado, caso em que a amostragem seguinte seria feita depois de decorridos os 5 min do início da coleta anterior. Este procedimento era repetido até totalizar as sete amostras, ou seja, durante 35 min após o início do escoamento de água na calha coletora. O intervalo de tempo compreendido entre o início da aplicação da chuva simulada e o início da coleta, foi registrado como tempo de início do escoamento superficial em cada parcela.

Durante o período de operação do simulador, a pressão de serviço era constantemente conferida (32 kPa) e, ao final de cada teste na parcela experimental, fazia-se a verificação da intensidade de precipitação real aplicada pelo simulador. De posse dos dados de pressão, intensidade de precipitação e altura dos bicos (2,30 m), procedia-se ao cálculo da energia cinética da chuva simulada utilizando-se, para isto, o programa computacional EnerChuva desenvolvido por Alves Sobrinho et al. (2001).

Tabela 2. Valores médios de umidade (Ui) do solo, \% base massa, momentos antes dos testes

\begin{tabular}{cccc}
\hline \multirow{2}{*}{$\mathbf{p}\left(\mathbf{m m ~ h}^{-\mathbf{1}}\right)$} & \multicolumn{3}{c}{ Ui (\%) } \\
\cline { 2 - 4 } & $\mathbf{0} \mathbf{- 5} \mathbf{~ c m}$ & $\mathbf{5} \mathbf{- 1 0} \mathbf{~ c m}$ & $\mathbf{1 0} \mathbf{- 2 0} \mathbf{~ c m}$ \\
40 & $27,00 \mathrm{Aa}$ & Sistema A - Pastagem \\
60 & $26,41 \mathrm{Aa}$ & $26,39 \mathrm{Aa}$ & $27,10 \mathrm{Aa}$ \\
80 & $28,36 \mathrm{Aa}$ & $26,60 \mathrm{Aa}$ & $26,20 \mathrm{Aa}$ \\
100 & $29,13 \mathrm{Aa}$ & $28,29 \mathrm{Aa}$ & $28,01 \mathrm{Aa}$ \\
\multicolumn{3}{c}{ Sistema B - Plantio Direto } \\
40 & $29,29 \mathrm{Aa}$ & $29,25 \mathrm{Aa}$ & $29,58 \mathrm{Aa}$ \\
60 & $30,04 \mathrm{Aa}$ & $29,76 \mathrm{Aa}$ & $30,03 \mathrm{Aa}$ \\
80 & $29,18 \mathrm{Aa}$ & $28,98 \mathrm{Aa}$ & $29,48 \mathrm{Aa}$ \\
100 & $29,16 \mathrm{Aa}$ & $29,33 \mathrm{Aa}$ & $29,86 \mathrm{Aa}$ \\
\hline
\end{tabular}

Médias seguidas com letra maiúscula na coluna e minúscula na linha não diferem entre si a $5 \%$ de significância pelo Teste de Tukey
No final da avaliação de campo, as amostras foram encaminhadas ao laboratório, em frascos vedados, a fim de se realizar as medições da massa de solo e do volume de água escoado, no qual, as amostras foram colocadas em becker de um litro e lhes sendo acrescentadas gotas de ácido clorídrico (1 N) para a floculação do material sólido em suspensão; em seguida, o excesso de água era retirado e o volume quantificado e registrado. As amostras de material sólido assim obtidas foram então colocadas em estufa, a temperatura de $60{ }^{\circ} \mathrm{C}$, por período de tempo necessário à completa evaporação da água contida nas mesmas. A água retida nas amostras foi determinada e o valor obtido foi acrescido ao volume de água inicialmente registrado. A massa do material sólido foi obtida por pesagem determinando-se, em seguida, densidade de partículas, conforme EMBRAPA (1997).

Em cada sistema de cultivo compararam-se as perdas de solo e de água referentes às diferentes intensidades de precipitação e, posteriormente, aplicada a análise conjunta entre os sistemas A e B, com o objetivo de se comparar o efeito da mesma intensidade de precipitação aplicada aos dois sistemas de cultivo.

Após os testes de campo, foram retiradas amostras indeformadas de solo das parcelas experimentais, em duas profundidades (0-5 e 5-20 cm), para análises físicas de densidade do solo, porosidade total, macroporosidade e microporosidade do solo, de acordo com os critérios estabelecidos em EMBRAPA (1997). Determinou-se, ainda, a distribuição de agregados para essas duas profundidades. Para a determinação da distribuição de agregados pelo método de peneiramento úmido, foram retirados blocos de solo com estrutura natural que, após secados ao ar, foram passados em peneiras de 9,52 e 4,76 mm e empregados nas análises posteriores e os agregados retidos na peneira de 4,76 mm. A análise de estabilidade de agregados foi realizada procedendo-se ao peneiramento, durante $15 \mathrm{~min}$, em jogo de peneiras com malhas de 2,0; 1,0; 0,5; e 0,105 mm, dentro do recipiente contendo água. Adotou-se, como índices de estabilidade, o diâmetro médio geométrico e o diâmetro médio ponderado, cujos cálculos foram feitos seguindo-se a proposta de Kemper \& Rosenau (1986).

Para avaliar o efeito dos tratamentos nos sistemas de cultivo e se obter uma estimativa da variância residual, fez-se análise de variância dos dados obtidos, com a posterior aplicação do Teste de Tukey a 5\%, para a comparação de médias. A análise estatística foi realizada utilizando-se o programa SANEST (Sistema de Análise Estatística).

\section{RESULTADOS E DISCUSSÃO}

A intensidade de precipitação prevista (Ip), o tempo de início do escoamento, intensidade de precipitação real e energia cinética dos testes de campo realizados com o simulador de chuva, para determinação das perdas de massa de solo e volume de água escoado, nos sistemas A (pastagem) e B (plantio direto), são apresentados na Tabela 3.

Em todas as situações, nota-se diminuição do tempo de início de escoamento superficial à medida que a intensidade 
Tabela 3. Intensidade de precipitação prevista (Ip) e valores médios do tempo de início do escoamento (Ti), intensidade de precipitação real (Ip real) e energia cinética (EC)

\begin{tabular}{|c|c|c|c|}
\hline Ip $\left(m m h^{-1}\right)$ & $\mathrm{Ti}(\mathrm{min})$ & Ip real $\left(\mathrm{mm} \mathrm{h}^{-1}\right)$ & $E c\left(\mathrm{~J} \mathrm{~m}^{-2}\right)$ \\
\hline & \multicolumn{3}{|c|}{ Sistema A - Pastagem } \\
\hline 40 & 34,59 & 37,42 & 528,29 \\
\hline 60 & 14,20 & 59,26 & 836,62 \\
\hline 80 & 4,97 & 80,31 & $1.133,80$ \\
\hline \multirow[t]{2}{*}{100} & 3,46 & 100,28 & $1.415,73$ \\
\hline & \multicolumn{3}{|c|}{ Sistema B - Plantio Direto } \\
\hline 40 & 46,35 & 39,60 & 559,06 \\
\hline 60 & 20,67 & 59,01 & 833,09 \\
\hline 80 & 8,37 & 78,64 & $1.110,22$ \\
\hline 100 & 6,15 & 95,24 & $1.344,58$ \\
\hline
\end{tabular}

de precipitação é aumentada. A análise dos dados evidencia uma correlação negativa entre a intensidade de precipitação e o tempo de início do escoamento, nos dois sistemas de cultivo $\left(R_{A}=-0,93\right.$ e $\left.R_{B}=-0,94\right)$.

O sistema A (pastagem) apresentou, em geral, menor intervalo de tempo para o início do escoamento superficial em todos os tratamentos. Isto pode estar associado com aspectos relativos à rugosidade superficial, cobertura do solo e, principalmente, com a macroporosidade superficial (0 a $5 \mathrm{~cm}$ ), além da detenção superficial da enxurrada no interior das mini depressões que surgem naturalmente pelo uso de equipamentos agrícolas.

Comparando os sistemas de plantio convencional, cultivo mínimo e plantio direto, Barcelos et al. (1999) observam que o tempo de início de escoamento foi inferior no plantio direto, por apresentar menor rugosidade superficial em relação aos demais, visto que no plantio convencional e no cultivo mínimo são utilizadas determinadas práticas que promovem a formação de rugosidades na superfície do solo que, por sua vez, favorece a maior retenção da água superficial.

Os valores de intensidade de aplicação não foram exatamente iguais nos quatro tratamentos, em virtude das características operacionais e de montagem do equipamento no campo, mas o percentual relativo de suas respectivas energias cinéticas foi superior a $88 \%$, bem acima, portanto, do valor mínimo necessário proposto por Meyer \& McCune (1958) que é de 75\%. Considerando-se que a energia cinética da chuva é uma das propriedades que determinam a maior ou menor desagregação superficial do solo (Agassi \& Bradford, 1999), contribuindo para a formação do selamento superficial, assume-se que as variações observadas na intensidade de precipitação realmente aplicada em cada tratamento, em relação às planejadas, não influenciaram na magnitude dos valores de energia cinética.

Os valores médios de densidade do solo, macroporosidade, microporosidade e volume total de poros do solo nas profundidades de 0 a $5 \mathrm{~cm}$ e de 5 a $20 \mathrm{~cm}$, para os sistemas experimentais em estudo, pastagem e plantio direto em sistema de integração agricultura-pecuária, são apresentados na Tabela 4.

Analisando-se os resultados obtidos, verifica-se que para a densidade do solo, microporosidade e volume total de po-
Tabela 4. Valores médios da densidade do solo, macroporosidade, microporosidade e volume total de poros nos dois sistemas avaliados

\begin{tabular}{|c|c|c|}
\hline \multirow{2}{*}{ Sistemas } & \multicolumn{2}{|c|}{ Profundidade (cm) } \\
\hline & $0-5$ & $5-20$ \\
\hline & \multicolumn{2}{|c|}{ Densidade do solo (Mg m³) } \\
\hline A (pastagem) & $1,29 \mathrm{Aa}$ & $1,27 \mathrm{Aa}$ \\
\hline \multirow[t]{2}{*}{ B (plantio direto) } & $1,25 \mathrm{Aa}$ & $1,37 \mathrm{Aa}$ \\
\hline & \multicolumn{2}{|c|}{ Macroporosidade (\%) } \\
\hline A (pastagem) & $10,53 \mathrm{Ba}$ & $13,66 \mathrm{Aa}$ \\
\hline \multirow[t]{2}{*}{ B (plantio direto) } & $15,78 \mathrm{Aa}$ & $6,84 \mathrm{Bb}$ \\
\hline & \multicolumn{2}{|c|}{ Microporosidade (\%) } \\
\hline A (pastagem) & 46,34 Аa & $44,61 \mathrm{Aa}$ \\
\hline \multirow[t]{2}{*}{ B (plantio direto) } & $43,83 \mathrm{Aa}$ & $47,19 \mathrm{Aa}$ \\
\hline & \multicolumn{2}{|c|}{ Volume Total de Poros (\%) } \\
\hline A (pastagem) & $56,87 \mathrm{Aa}$ & $58,67 \mathrm{Aa}$ \\
\hline B (plantio direto) & $59,62 \mathrm{Aa}$ & $54,04 \mathrm{Aa}$ \\
\hline
\end{tabular}

Médias seguidas com letra maiúscula na coluna e minúscula na linha não diferem entre si a $5 \%$ de significância pelo Teste de Tukey

ros do solo, não houve diferença significativa nos dois sistemas, considerando-se as duas profundidades avaliadas. Embora a densidade do solo tenha sido semelhante nos dois sistemas e nas duas profundidades avaliadas, nota-se tendência de menor densidade na camada mais profunda das áreas com pastagem. Este fato pode ser atribuído à influência do sistema radicular das gramíneas, que geralmente contribuem para uma estrutura melhor do solo, principalmente pela deposição de matéria orgânica uma vez que, segundo Vitorino (1986), maiores densidades em posições mais profundas podem ser decorrentes da redução da matéria orgânica. Nos sistemas de cultivo em que havia pastagem, o sistema radicular estava bem desenvolvido, com grande concentração nos primeiros $20 \mathrm{~cm}$.

No sistema A (pastagem) a macroporosidade foi maior na profundidade de 5 a $20 \mathrm{~cm}$, enquanto no sistema B (plantio direto) foi maior na profundidade de 0 a $5 \mathrm{~cm}$. Os maiores valores de macroporosidade estão associados aos menores valores de densidade do solo, fato evidenciado por uma correlação negativa $(R=-0,93)$ entre esses atributos.

Na Tabela 5 tem-se os valores de diâmetro médio geométrico (DMG) e diâmetro médio ponderado (DMP) dos agregados, após a superfície do solo ter sido submetida às diferentes intensidades de precipitação.

Comparando-se os sistemas cultivados, vê-se que o sistema A (pastagem) apresentou, na camada de 0 a $5 \mathrm{~cm}$, os maiores valores de DMG e DMP em relação ao sistema B (plantio direto). Esta diferença entre os sistemas representa melhor estrutura física nas áreas sob pastagem ocasionada, possivelmente, pela ação do sistema radicular das gramíneas e do maior teor de matéria orgânica, que atua como elemento estabilizador da estrutura, promovendo a formação de agregados maiores e mais estáveis.

Constata-se diminuição dos valores de DMG e de DMP a medida em que aumenta a profundidade, corroborando com os dados de Lima et al. (2003), que consideram esta ocorrência motivada, provavelmente, pela diminuição dos teores de carbono-orgânico sempre que a profundidade do solo aumenta. Resultados idênticos foram encontrados por Vitorino 
Tabela 5. Valores de diâmetro médio geométrico e de diâmetro médio ponderado

\begin{tabular}{|c|c|c|c|c|}
\hline \multirow{2}{*}{ Sistemas } & \multicolumn{4}{|c|}{ Profundidade (cm) } \\
\hline & $0-5$ & $5-20$ & $0-5$ & $5-20$ \\
\hline & \multicolumn{4}{|c|}{ Intensidade de Precipitação $\left(\mathrm{mm} \mathrm{h}^{-1}\right)$} \\
\hline & \multicolumn{2}{|c|}{40} & \multicolumn{2}{|c|}{60} \\
\hline & \multicolumn{4}{|c|}{ Diâmetro Médio Geométrico - DMG (mm) } \\
\hline A (pastagem) & $2,23 \mathrm{~A}$ & $0,89 \mathrm{~A}$ & $2,77 \mathrm{~B}$ & $1,29 \mathrm{~B}$ \\
\hline \multirow[t]{2}{*}{ B (plantio direto) } & $1,65 \mathrm{~B}$ & $0,85 \mathrm{~A}$ & $1,78 \mathrm{C}$ & 0,630 \\
\hline & \multicolumn{4}{|c|}{ Diâmetro Médio Ponderado - DMP (mm) } \\
\hline A (pastagem) & $3,65 \mathrm{~A}$ & $1,95 \mathrm{~A}$ & $3,98 \mathrm{~B}$ & $2,51 \mathrm{~B}$ \\
\hline \multirow[t]{4}{*}{ B (plantio direto) } & $2,79 \mathrm{~B}$ & $1,61 \mathrm{~A}$ & $2,98 \mathrm{C}$ & 1,190 \\
\hline & \multicolumn{4}{|c|}{ Intensidade de Precipitação $\left(\mathrm{mm} \mathrm{h}^{-1}\right)$} \\
\hline & \multicolumn{2}{|c|}{80} & \multicolumn{2}{|c|}{100} \\
\hline & \multicolumn{4}{|c|}{ Diâmetro Médio Geométrico - DMG (mm) } \\
\hline A (pastagem) & $2,71 \mathrm{~A}$ & $1,26 \mathrm{~A}$ & $2,51 \mathrm{~B}$ & $1,37 \mathrm{~B}$ \\
\hline \multirow[t]{2}{*}{ B (plantio direto) } & $1,71 \mathrm{~B}$ & $1,12 \mathrm{~A}$ & $1,99 \mathrm{C}$ & $1,00 \mathrm{C}$ \\
\hline & \multicolumn{4}{|c|}{ Diâmetro Médio Ponderado - DMP (mm) } \\
\hline A (pastagem) & $4,00 \mathrm{~A}$ & $2,25 \mathrm{~A}$ & $3,89 \mathrm{~B}$ & $2,66 \mathrm{~B}$ \\
\hline B (plantio direto) & $2,14 \mathrm{~B}$ & $1,94 \mathrm{~A}$ & $3,10 \mathrm{C}$ & 1,920 \\
\hline
\end{tabular}

Médias seguidas da mesma letra maiúscula na coluna, para a mesma variável, não diferem entre si a $5 \%$ pelo Teste de Tukey

(1986), que também relaciona este fato à maior taxa de matéria orgânica na região superficial do solo, considerando, ainda que a maior estabilidade de agregados na superfície possa estar relacionada aos fenômenos de expansão e contração, mais intensos nesta parte do perfil do solo; desta forma, os valores diferenciados de DMP, associados a outras condições de superfície, exerceram influência nas perdas de água e solo por erosão hídrica, conforme relatado também por Volk et al. (2004).

Os valores médios acumulados da massa de solo e volume de água escoado após aplicação de precipitação pluvio- métrica simulada sobre os dois sistemas em estudo, são apresentados na Tabela 6 .

Verifica-se ausência de diferença significativa nas perdas de solo no sistema $\mathrm{A}$, quando submetido às chuvas simuladas com intensidades de 40 e $60 \mathrm{~mm} \mathrm{~h}^{-1}$; já a chuva simulada de $60 \mathrm{~mm} \mathrm{~h}^{-1}$ ocasionou perdas de solo estatisticamente iguais às ocorridas com as chuvas de 40 e $80 \mathrm{~mm} \mathrm{~h}^{-1}$, diferindo apenas em relação à correspondente a $100 \mathrm{~mm} \mathrm{~h}^{-1}$. No sistema B (plantio direto) não houve diferença de perdas de solo para as precipitações de 40, 60 e $80 \mathrm{~mm} \mathrm{~h}^{-1}$, porém estas diferiram mais acentuadamente com a de $100 \mathrm{~mm} \mathrm{~h}^{-1}$.

Estabelecendo-se uma análise comparativa entre os dois sistemas de cultivo, verifica-se que, para a mesma intensidade de precipitação, não ocorreu diferença significativa entre as perdas de solo para as intensidades de 60 e $80 \mathrm{~mm} \mathrm{~h}^{-1} \mathrm{o}$ que se deu, porém, nas intensidades de 40 e $100 \mathrm{~mm} \mathrm{~h}^{-1}$; entretanto, pode-se afirmar que, em média, houve tendência a maiores perdas de solo na área com plantio direto que na área de pastagem.

Dechen et al. (1981), trabalhando sobre um Latossolo Roxo em condições de chuva natural, em Campinas, SP, constataram que, em geral, as gramíneas foram mais eficazes que as leguminosas na diminuição das perdas de solo, em todos os estádios de desenvolvimento das culturas, atribuindo este fato ao sistema radicular das gramíneas, que atua como importante agente reestruturador da camada arável, tornando o solo mais resistente à ação do impacto desagregador das gotas de chuva. Esta maior eficiência do sistema radicular das gramíneas em relação à das leguminosas, foi também mencionada por Boni et al. (1994).

Os maiores valores DMG e DMP encontrados para o sistema A (pastagem) em relação ao B, caracterizando melhor estrutura física no primeiro, podem ter contribuído para propiciar menores perdas de solo nesse sistema. Pode-se considerar,

Tabela 6. Valores médios acumulados de perdas de solo e água, em áreas de integração agricultura-pecuária, com pastagem e plantio direto, sob diferentes intensidades de precipitação

\begin{tabular}{|c|c|c|c|c|c|c|c|c|}
\hline \multirow{3}{*}{ Tempo (min) } & \multicolumn{8}{|c|}{ Intensidade de Precipitação $\left(\mathrm{mm} \mathrm{h}^{-1}\right)$} \\
\hline & 40 & 60 & 80 & 100 & 40 & 60 & 80 & 100 \\
\hline & \multicolumn{4}{|c|}{ Perdas de solo $\left(\mathrm{g} \mathrm{m}^{-2}\right)$} & \multicolumn{4}{|c|}{ Perdas de água $\left(10^{-3} \mathrm{~m}^{3} \mathrm{~m}^{-2}\right)$} \\
\hline & \multicolumn{8}{|c|}{ Sistema A (pastagem) } \\
\hline 05 & 0,32 & 0,26 & 0,93 & 1,31 & 0,26 & 1,34 & 2,02 & 3,02 \\
\hline 10 & 0,54 & 0,52 & 1,45 & 2,50 & 0,61 & 2,91 & 4,48 & 7,73 \\
\hline 15 & 0,77 & 0,68 & 2,03 & 3,44 & 1,14 & 4,65 & 7,16 & 13,02 \\
\hline 20 & 0,91 & 0,97 & 2,68 & 4,29 & 1,48 & 6,49 & 10,18 & 18,44 \\
\hline 25 & 1,06 & 1,34 & 3,40 & 5,11 & 2,29 & 8,38 & 13,97 & 23,85 \\
\hline 30 & 1,20 & 1,63 & 4,03 & 5,71 & 2,88 & 10,41 & 17,79 & 29,13 \\
\hline \multirow[t]{2}{*}{35} & $1,33 \mathrm{Cb}$ & $1,89 \mathrm{Bca}$ & 4,49 Aba & $6,18 \mathrm{Ab}$ & $3,45 \mathrm{Ca}$ & $12,43 \mathrm{BCa}$ & $21,04 \mathrm{ABa}$ & $34,64 \mathrm{Aa}$ \\
\hline & \multicolumn{8}{|c|}{ Sistema B (plantio direto) } \\
\hline 05 & 0,40 & 0,71 & 0,91 & 0,63 & 0,11 & 0,10 & 0,47 & 0,44 \\
\hline 10 & 0,84 & 1,22 & 1,41 & 2,01 & 0,26 & 0,31 & 1,06 & 1,71 \\
\hline 15 & 1,20 & 1,63 & 2,06 & 3,78 & 0,44 & 0,57 & 1,82 & 3,52 \\
\hline 20 & 1,57 & 2,08 & 2,67 & 5,67 & 0,64 & 0,86 & 2,70 & 5,47 \\
\hline 25 & 1,93 & 2,50 & 3,25 & 7,31 & 0,85 & 1,21 & 3,54 & 7,51 \\
\hline 30 & 2,39 & 2,74 & 3,80 & 8,91 & 1,08 & 1,58 & 4,47 & 9,77 \\
\hline 35 & $2,78 \mathrm{Ba}$ & $3,07 \mathrm{Ba}$ & $4,38 \mathrm{Ba}$ & $10,50 \mathrm{Aa}$ & 1,34 Ba & $2,00 \mathrm{Bb}$ & $5,50 \mathrm{Bb}$ & $12,14 \mathrm{Ab}$ \\
\hline
\end{tabular}


ainda, que tais diferenças relativas às perdas de solo também estejam associadas à maior densidade de massa vegetal na área do sistema A, que favorece melhor absorção do impacto das gotas de chuva, proporcionando menor desagregação das partículas.

As perdas de água no sistema B (plantio direto) não revelaram diferenças significativas entre as intensidades de precipitação de 40, 60 e $80 \mathrm{~mm} \mathrm{~h}^{-1}$, porém foram diferentes em relação às de $100 \mathrm{~mm} \mathrm{~h}^{-1}$. Em geral, é de se esperar, realmente, que o aumento da intensidade de precipitação proporciona maiores perdas de água. Comparando-se a mesma intensidade aplicada nos dois sistemas de cultivo, vê-se que, com exceção da intensidade de $40 \mathrm{~mm} \mathrm{~h}^{-1}$, houve diferença com relação aos volumes de água escoados para as demais intensidades aplicadas (60, 80 e $100 \mathrm{~mm} \mathrm{~h}^{-1}$ ).

Os maiores valores médios para o escoamento superficial no sistema sob pastagem, podem ter sua ocorrência associada à menor rugosidade superficial e à possibilidade da presença de uma camada delgada de solo com estrutura laminar, motivada pelo pisoteio animal, o que está de acordo com Vitorino (1986), que verificou que este evento pode promover compactação na camada superficial nos períodos mais úmidos. Devese considerar, também, que as parcelas com pastagem possuíam, visualmente, quantidades de massa vegetal maiores do que a da área de plantio direto, porém não totalmente depositada sobre a superfície. Constituía, na maior parte, uma massa vegetal viva com certa elevação em relação à superfície, sem proporcionar a mesma resistência ao escoamento superficial que a conferida pela resteva de soja (sistema B).

Analisando-se os dados da Tabela 6, já apresentada, considera-se que, assim como apresentado por Amorim et al. (2001) e Carvalho et al. (2002), com o aumento dos valores de energia cinética observou-se aumento da vazão de escoamento superficial proporcionado pelo aumento da intensidade de precipitação. Este fato pode ter ocasionado uma concentração do fluxo de água com a formação de caminhos preferenciais de escoamento de água, aumentando a partir de certo tempo de aplicação, elevando a sua capacidade de transporte superficial.

Analisando-se o efeito da intensidade de precipitação nas perdas de solo e de água, verifica-se que no sistema A (pastagem), ao se variar a intensidade de precipitação de 40 para $100 \mathrm{~mm} \mathrm{~h}^{-1}$, ocorre aumento de aproximadamente 4,6 vezes nas perdas de solo e 10 vezes nas perdas de água. No sistema B (plantio direto), com a mesma variação nos valores da chuva simulada, se dá um aumento de 3,8 vezes nas perdas de solo e 9 vezes nas perdas de água.

\section{CONCLUSÕES}

1. Observou-se que em áreas com pastagem há tendência de maior densidade na camada mais superficial do solo (0 a $5 \mathrm{~cm}$ ).

2. Verificou-se maior valor de macroporosidade na camada de 0 a $5 \mathrm{~cm}$ de profundidade, em cultivos sob plantio direto em comparação com pastagem.

3. Os valores de diâmetro médio geométrico e pondera- do, na camada de 0 a $5 \mathrm{~cm}$, foram maiores em solo cultivado com pastagem que com plantio direto, independente da intensidade de precipitação.

4. De maneira geral, o sistema de integração agriculturapecuária sob plantio direto apresenta perdas de solo mais acentuadas que o sistema sob pastagem, tendo ocorrido o inverso com as perdas de água.

5. As perdas de solo e as de água aumentam com a aplicação de intensidades de precipitação mais elevadas.

\section{LITERATURA CITADA}

Agassi, M.; Bradford, J. M. Methodologies for interril soil erosion studies. Soil and Tillage Research. New York, v.49, n.4, p.277-287, 1999.

Alves Sobrinho, T. Desenvolvimento de um infiltrômetro de aspersão portátil. Viçosa: UFV, 1997. 85p. Tese Doutorado

Alves Sobrinho, T.; Carvalho, D. F.; Aquino, R. M.; Montebeller, C. A. Programa computacional para a definição de parâmetros hidráulicos utilizados na determinação da energia cinética da chuva simulada em infiltrômetro de aspersão. Engenharia Rural, Piracicaba, v.12, n.1, p.28-35, 2001.

Amorim, R. S. S.; Silva, D. D.; Pruski, F. F.; Matos, A. T. Influência da declividade do solo e da energia cinética de chuvas simuladas no processo de erosão entre sulcos. Revista Brasileira de Engenharia Agrícola e Ambiental, Campina Grande, v.5, n.1, p.124-130, 2001.

Barcelos, A. A.; Cassol, E. A.; Denardin, J. E. Infiltração de água em um Latossolo Vermelho-escuro sob condições de chuva intensa em diferentes sistemas de manejo, Revista Brasileira de Ciência do Solo, Viçosa, v.23, n.1, p.35-43, 1999.

Boni, N. R.; Espindola, C. R.; Guimarães, E. C. Uso de leguminosas na recuperação de um solo decapitado. In: Simpósio SulAmericano, 1 e Simpósio Nacional "Recuperação de áreas degradadas”, 2, Foz do Iguaçu, 1994, Anais... Foz do Iguaçu: Fundação de Pesquisas Florestais do Paraná, 1994, p.563-568.

Carpenedo, V.; Mielniczuk, J. Estado de agregados e qualidade de agregados de Latossolos Roxos, submetidos a diferentes sistemas de manejo. Revista Brasileira de Ciência do Solo, Piracicaba, v.14, n.1 p.99-105, 1990.

Carvalho, D. F.; Montebeller, C. A.; Cruz, E. S.; Ceddia, M. B.; Lana, A. M. Q. Perda de solo e água em um Argissolo Vermelho Amarelo, submetido a diferentes intensidades de chuva simulada. Revista Brasileira de Engenharia Agrícola e Ambiental, Campina Grande, v.6, n.3, p.385-389, 2002.

Cogo, N. P.; Levien, R.; Schwarz, R. A. Perdas de solo e água por erosão hídrica influenciadas por métodos de preparo, classes de declive e níveis de fertilidade do solo. Revista Brasileira de Ciência do Solo, Viçosa, v.27, n.5, p.743-753, 2003.

Dechen, S. L. F.; Lombardi Neto, F.; Castro, O. M. Gramíneas e leguminosas e seus restos culturais no controle da erosão em Latossolo Roxo. Campinas. Revista Brasileira de Ciência do Solo, Piracicaba, v.5, n.1, p.133-137, 1981.

Eltz, F. L. F.; Mehl, H. U.; Reichert, J. M. Perdas de solo e água em entressulcos em um Argissolo Vermelho-Amarelo submetido a quatro padrões de chuva. Revista Brasileira de Ciência do Solo, Viçosa, v.25, n.3, p.485-493, 2001. 
EMBRAPA - Empresa Brasileira de Pesquisa Agropecuária - Centro Nacional de Pesquisa de Solos: Manual de métodos de análise de solo. 2.ed. Rio de Janeiro: Embrapa-CNPS, 1997. 212p.

Hernani, L. C.; Salton, J. C.; Fabrício, A. C.; Dedecek, R.; Alves Júnior, M. Perdas por erosão e rendimentos de soja e trigo em diferentes sistemas de preparo de um Latossolo Roxo de Dourados, MS, Revista Brasileira de Ciência do Solo, Viçosa, v.21, n.4, p.667-676, 1997.

Kemper, W. D.; Rosenau, R. C. Aggregate stability and size distribution. In: Klute, A., Methods of soil analisis. 2.ed. Madison, American Society of Agronomy, Soil Science Society of América, 1986, p.425-441.

Lima, C. L. R.; Pauletto, E. A.; Gomes, A. S.; Silva, J. B. Estabilidade de agregados de um planossolo sob diferentes sistemas de manejo. Revista Brasileira de Ciência do Solo, Viçosa, v.27, n.1, p.199-205, 2003.

Meyer, L. D.; Mccune, D. L. Rainfall simulator for runoff plots. Agricultural Engineering, St. Joseph, v.39, n.1, p.644648, 1958.
Schick, J.; Bertol, I.; Batistela, O.; Balbinot Júnior, A. A. Erosão hídrica em Cambissolo Húmico alumínico submetido a diferentes sistemas de preparo e cultivo do solo. Revista Brasileira de Ciências do Solo, Viçosa, v.24, n.2, p.427-436, 2000.

Silva, M. L. N.; Curi, N.; Lima, J. M.; Ferreira, M. M. Avaliação de métodos indiretos de determinação da erodibilidade de Latossolos brasileiros. Pesquisa Agropecuária Brasileira, Brasília, v.35, n.6, p.1207-1220, 2000.

Varella, C. A. A. Efeito dos sistemas de cultivo nas perdas de água e solo. Seropédica: UFRRJ, 1999. 93p. Dissertação Mestrado

Vitorino, A. C. T. Caracterização e interpretação para uso agrícola, de solos de terraço fluvial, no médio Rio Doce, Município de Córrego Novo, MG. Viçosa: UFV, 1986, 95p. Dissertação Mestrado

Volk, L. B. S.; Cogo, N. P.; Streck, E. V. Erosão hídrica influenciada por condições físicas de superfície e subsuperfície do solo resultantes do seu manejo, na ausência de cobertura vegetal. Revista Brasileira de Ciências do Solo, Viçosa, v.28, n.4, p.585-596, 2004. 